\title{
Plasmon enhancement of fluorescence of phthalocyanines metallocomplexes in solutions of silver nanoparticles
}

\author{
Aleksandr Starukhin ${ }^{1, *}$, Vladimir Apyari ${ }^{2}$, Aleksander Gorski ${ }^{3}$, Andrei Ramanenka ${ }^{1}$, and \\ Aleksei Furletov ${ }^{2}$ \\ ${ }^{1}$ Stepanov Institute of Physics, National Academy of Sciences of Belarus, 220072 Minsk, Belarus \\ ${ }^{2}$ Lomonosov Moscow State University, Department of Chemistry, 119991 Moscow, Russia \\ ${ }^{3}$ Institute of Physical Chemistry, Polish Academy of Sciences, 01-224 Warsaw, Poland
}

\begin{abstract}
A method of creation of aqueous solutions with silver nanoparticles for studying of fluorescence of hydrophobic compounds has been proposed for metallocomplexes of phthalocyanines. The effect of silver nanoparticles on the fluorescence of phthalocyanines metallocomplexes at room and low temperatures was studied. The addition of silver nanoparticles leads to plasmonic enhancement of signals in fluorescence and fluorescence excitation spectra of the compounds of interest from 1,5 to more than 7 times. The lifetimes and quantum yield of fluorescence were measured for solutions of metallophthalocyanines in binary mixtures and in binary mixtures with the addition of silver triangular nanoplates with shells of silicon dioxide.
\end{abstract}

Fluorescence for a number of chromophores can be enhanced upon their interaction with nanoparticles of various noble metals. Such types of effects are called plasmon enhanced fluorescence and such methods have a lot of interesting analytical applications as optical sensors in colloidal solutions or in the solid state [1]. It is well known, that phthalocyanines have been widely used in organic solar cells or as effective photosensitizers in cancer treatment. The parent phthalocyanines possess hydrophobic properties and cannot be dissolved in water. The main idea of our concept was to create a methodology for observation of the effects of plasmon enhancement of fluorescence for hydrophobic organometallic compounds using aqueous solutions of silver nanoparticles (AgNPs).

In this report we presented the data on the conventional and surface-enhanced fluorescence and excitation of fluorescence spectra of $\mathrm{Mg}$-phthalocyanine $(\mathrm{Mg}-\mathrm{Pc})$ and $\mathrm{Zn}$ phthalocyanine $(\mathrm{Zn}-\mathrm{Pc})$, the structures of which are shown in Fig. 1. The above mentioned compounds were preliminary dissolved in dimethyl sulfoxide $\left(\mathrm{C}_{2} \mathrm{H}_{6} \mathrm{OS}\right)$ or ethanol $\left(\mathrm{C}_{2} \mathrm{H}_{5} \mathrm{OH}\right)$ with concentration about $10^{-8} \mathrm{M}$. After that, $600 \mu \mathrm{l}$ of prepared solutions was mixed with $2400 \mu \mathrm{l}$ of deionized water (for recording of the conventional spectra) or water solution of AgNPs. AgNPs of two types have been used: 1. triangular Ag nanoplate (average edge length - $52 \mathrm{~nm}$, thickness $-3.8 \mathrm{~nm}$ ); 2. silver triangular nameplate's of $\mathrm{Ag}$

\footnotetext{
*Corresponding author: : $\underline{\text { starukhin@ mail.ru }}$
} 
isolated in shell of $\mathrm{SiO}_{2}\left(\mathrm{AgNPs}-\mathrm{SiO}_{2}\right)$ with using the following method. The solution of $3.1 \mathrm{ml} \mathrm{AgNPs}$ were mixed at stirring with $6,9 \mathrm{ml}$ of $\mathrm{H}_{2} \mathrm{O}$ and $0,66 \mathrm{ml}$ of $0,3 \mathrm{M} \mathrm{Na}_{2} \mathrm{SiO}_{3}$. Then $\mathrm{pH}$ was adjusted to 6,8-7,2 acetic acid. After several hours $\mathrm{AgNPs}-\mathrm{SiO}_{2}$ were triply washed with $10 \mathrm{ml}$ of $\mathrm{H}_{2} \mathrm{O}$ at centrifugation/

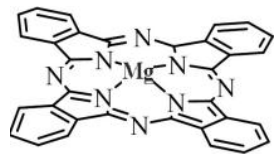

a

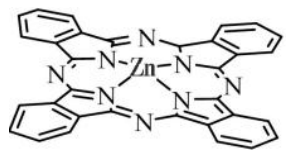

b

Fig. 1. Chemical structures of $\mathrm{Mg}-\mathrm{Pc}$ (a) and $\mathrm{Zn}-\mathrm{Pc}(\mathrm{b})$

The fluorescence and excitation of fluorescence spectra of $\mathrm{Mg}-\mathrm{Pc}$ in various solutions are shown in Fig. 2. Upon using of $\mathrm{AgNPs}_{-} \mathrm{SiO}_{2}$, a plasmonic enhancement of fluorescence signals by more than 7 times of signals has been recorded in fluorescence and excitation of fluorescence spectra.

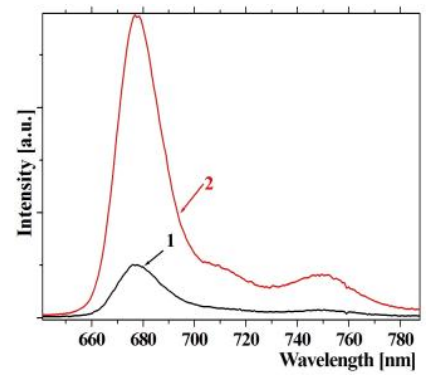

a

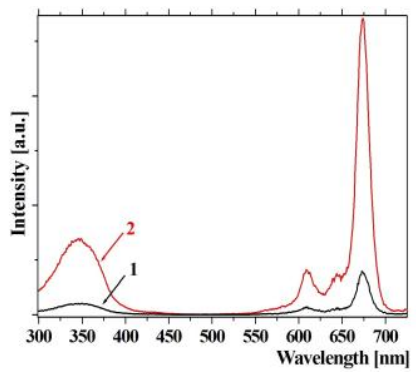

$\mathrm{b}$

Fig. 2. Fluorescence spectra (a) at $\lambda_{\text {exc. }}=350 \mathrm{~nm}$ and excitation of fluorescence (b) spectra at $\lambda_{\text {em. }}=$ $750 \mathrm{~nm}$ of $\mathrm{Mg}-\mathrm{Pc}$ in binary mixture of $\mathrm{H}_{2} \mathrm{O}-\mathrm{C}_{2} \mathrm{H}_{6} \mathrm{OS}$ (4:1): 1 - without $\mathrm{AgNPs}^{-S_{i O}}$;2 - with AgNPs$\mathrm{SiO}_{2}$ at $293 \mathrm{~K}$

The growth of fluorescence signals with factor more than 7 times is difficult to explain, because the quantum yield of fluorescence for $\mathrm{Mg}-\mathrm{Pc}$ in tetrahydrofuran (THF) is 0.54 (absolute measurements) and cannot exceed 1 when using of $\mathrm{AgNPs}_{-} \mathrm{SiO}_{2}$. In order to interpret the above mentioned data, the lifetimes and relative fluorescence quantum yields for $\mathrm{Mg}-\mathrm{Pc}$ and $\mathrm{Zn}-\mathrm{Pc}$ solutions in binary mixtures without and with $\mathrm{AgNPs}-\mathrm{SiO}_{2}$ were measured. The lifetime of the singlet state of $\mathrm{Mg}-\mathrm{Pc}$ in THF is $6.6 \mathrm{~ns}$, in $\mathrm{H}_{2} \mathrm{O}-\mathrm{C}_{2} \mathrm{H}_{6} \mathrm{OS}$ mixture - $5.8 \mathrm{~ns}$, and in the mixture with $\mathrm{AgNPs}-\mathrm{SiO}_{2}$ decreases to $4.9 \mathrm{~ns}$. For $\mathrm{Zn}-\mathrm{Pc}$, similar values are $3.8,3.2$, and $2.9 \mathrm{~ns}$, respectively. The fluorescence quantum yields was decreased from 0.54 (in THF) to $1.4 * 10^{-3}$ in the $\mathrm{H}_{2} \mathrm{O}-\mathrm{C}_{2} \mathrm{H}_{6} \mathrm{OS}$ mixture and reached $1 * 10^{-2}$ for the mixture with the addition of $\mathrm{AgNPs}-\mathrm{SiO}_{2}$.

This work was supported by grant RFFI № 18-53-00014-Bel and grant BRFFI № F18R-237.

\section{References}

1. E. Priyadarshini, N. Pradhan, Sensors Actuat. B: Chemical 238, 888 (2017) 